\title{
OJㅡㄹ
}

Volume 5, Issue 1 (2020), pp. 123-129

International Journal of

Multidisciplinary Perspectives in Higher Education ISSN: 2474-2546 Print/ ISSN: 2474-2554 Online https://ojed.org/jimphe

\section{"Yeah, We All Here Tryna Flourish": A Reflection on a Symposium on Eudaimonia and Music Learning}

\author{
Gareth Dylan Smith \\ Boston University, United States of America
}

\begin{abstract}
This article presents reflections on a symposium on eudaimonia and music learning, from the perspective of one of the organizers. The symposium had been planned as a traditional, in person event in the United States, but was held online in response to the 2020 COVID-19 pandemic. Despite shortcomings, the video-conferencing format possibly created a more democratized liminal space that served to dissolve hierarchies and broaden participation.
\end{abstract}

Keywords: (7-8) eudaimonia, eudaimonism, flourishing, symposium, reflection, liminal, democratic,

\section{Hosting a symposium during lockdown}

On May 22 and 23, 2020, Marissa Silverman and I hosted an online symposium on eudaimonia and music learning, to bring together colleagues whose research interests coalesce around what has become a topic of sustained interest in music education scholarship (e.g., Abrahams, 2020; van der Schyff, 2020). Eudaimonia provides a generative framework for exploring issues of meaning, identity, purpose, and ethical conduct for musicians and educators (Elliott \& Silverman, 2014). As Silverman and I have noted elsewhere, "the concept of 'eudaimonia' provides especially fertile ground for work in music and learning" because music makers "undertake their work and make sense of their lives and relationships in the 
full richness of the joys, challenges, ambiguities, and contradictions of the world" (Smith \& Silverman, 2020, p. viii). Exploring music learning through the lens of eudaimonia provides a fruitful way to discuss "aspects of how to live well and flourish-ideals which for many people music must involve making music" (Smith \& Silverman, 2020, p. viii). The title of this essay is taken from a rap penned by a group of music education students studying on the Popular Music Practicum course I taught at New York University during the spring semester, 2020 after we moved to remote teaching and learning. Readers may access the song here.

Silverman and I had intended to hold the symposium in-person and on-campus at Montclair State University in New Jersey, but with the advent of the COVID-19 pandemic it quickly became clear that this would not be possible, so we ran the event using Zoom. Having a Boston University Zoom account meant that we could welcome a large number of attendees without needing to worry about a time limit on meetings (although I admit to harboring probably-unfounded concerns about Zoom's willingness or capacity to let us run two, back to back, 12-hour conference days without disaster). We refunded all the pre-paid registration fees, cancelled the live music, hotel bookings, and campus catering, and advertised the event as open to all comers.

This Brief essay joins a growing body of work that reflects on internet use in music learning (Cayari, 2020; Smith et al, 2020) and on video conferencing in academia more generally ( $\mathrm{Li}$ et al., 2020). In what follows, I provide a brief introduction to eudaimonia, then consider the symposium in terms of timing and context, my experience of tension vis a vis the concept of eudaimonia, and affordances of the online symposium context. In conclusion, I summarize some of the symposium experience, its limits, and its liminality.

\section{Reflecting on the symposium \\ What is eudaimonia?}

Eudaimonia is the phenomenon of interest in eudaimonism, a philosophy of ethics dating back to Plato, expanded upon and popularized by Aristotle, developed and Christianized by Thomas Aquinas, and framed as the pursuit of happiness by Thomas Jefferson in the United States' Declaration of Independence (Conklin, 2015). More recently, there are two principal, complementary schools of eudaimonism - one more individualistic (e.g. Frankel, 1959; Norton, 1976; Smith, 2016; Waterman, 1993) and one more collaborative/collective in outlook (e.g. Boyce-Tillman 2020; Elliott \& Silverman, 2014; Seligman, 2011). Thinkers in both strands of inquiry are interested in addressing the question of what it means for humans to flourish (Smith \& Silverman, 2020). 
It seemed to me ironic and arguably somewhat in poor taste to be holding an event examining the complexities of human flourishing in music learning, at a time when many music teachers and musicians, along with everyone else, were finding it terribly difficult to flourish - personally, professionally, domestically, musically, collectively. Perhaps, though, holding this small symposium was now all the more important and vital. The presenters and previously registered attendees were largely college professors used to traveling to attend conferences around the world. All conferences this summer in our field had been cancelled, including the large biennial World Conference of the International Society for Music Education, and collective disappointment on social media and even in official emails was palpable. Our small symposium would hardly fill this tremendous void, but this would hopefully be a chance for interested, available parties to connect with colleagues, engage with ideas, and immerse ourselves in the familiar, heady conference experience of new names, new faces, and an overload of ideas, while trying to concentrate on multiple unique and intense talks over a full day, sharing a drink at a (virtual) bar with old and new colleagues, and then getting up to do it again the next day.

\section{Living the conceptual tensions of eudaimonia}

A compelling feature of scholarship on eudaimonia is the tension between emphasis on the virtue of pursuing one's true purpose - akin to Maslow's self-actualization (1962) and Jung's Individuation (1933) - and the imperative to enable flourishing for others. I felt very keenly the foregrounding of this friction as I hosted two-dozen Zoom checks in the days leading up to the event and then shuttered myself in my home office room for 10 hours a day, two days in a row, feverishly monitoring and moderating the symposium in the hope that it might in some small way benefit colleagues in the profession along with other musicians and learners we serve. All the while I was ignoring and deflecting responsibilities to my family, whom I banned from streaming media at all during the symposium, lest our home WiFi and the Zoom room crumble under the demands. My wife and daughter were both, as they always are, incredibly forgiving and flexible, and even brought me mugs of tea when I ran out of time to hydrate during the scheduled five-minutes breaks in programming (we had dispensed with coffee breaks and lunch breaks, since presenters were now in so many different time zones and juggling numerous domestic and professional responsibilities, in favor of an open-door policy for people to come and go as they were able).

\section{Unique affordances of the virtual space}

I was anxiously and keenly aware of the unsettling deterritorialized and de-centered place in which we were meeting to collaborate (Pignato \& Begany, 2015), but the gathering on this Zoom URL quickly began to feel 
like a liminal space for sharing ideas (Tuan, 1977), akin to the "third room" phenomenon of distributed telematic collaboration (Moir et al., 2016). Also recalling Moir et al. (2016), I felt the sudden and somewhat surreal, repeated removal from that liminal space each time I took out my earbuds between sessions. It felt almost like revisiting a parallel dimension, plunging back into that Zoom room to chair successive talks - as it were, re-entering the Narnian wardrobe.

Paper sessions were each scheduled for 45 minutes: 20-25 minutes for presenting followed by 15-20 minutes of discussion. While this would present an unduly, unusually intense schedule in an ordinary, in-person event, we felt that with people dispersed across time zones from Japan to California via Scandinavia and the United Kingdom, attendees would be likely to dip in and out of sessions - a freedom afforded us all by the Zoom format and a practice which is less convenient in the classrooms and ballrooms typical of conferences, where heavy doors slamming and creaking punctuate presentations loudly and rudely, however careful and unobtrusive one may try to be. We had anticipated an in-person gathering of 32 scholars, but we welcomed 93 individuals to Zoom over the two days (while this figure is encouraging, I recognize that the depth of most interpersonal encounters via Zoom was necessarily shallower than would or could be the case in an in-person setting). A presenter from Finland was still with the group sitting by a duskily sunlit window at 1.30AM local time, and following their paper, a presenter from Japan confessed to drinking a celebratory glass of wine with us all at 6.30am Tokyo time!

The space was, then, possibly more equitable and democratic in some respects than a traditional event. Once presenters had finished sharing screens and discussion began, each attendee was represented by a thumbnail image on the screen. This format seemed to dissolve some of the hierarchy of in-person conferences, as ranks and affiliations were less visible and everyone's presence was accorded identical room on the screen and equal access to the chat box and virtual "mic". Paper contents often became secondary in the discussions, and I (in my role as moderator) frequently allowed conversation to wander, so as to democratize the space and allow attendees to flourish here, in this particular, peculiar moment - to say what they needed to say. Frequent topics of diversion included musicians and teachers in attendance trying to understand direct application of ideas in their own professional contexts: how might we facilitate flourishing for our students, and help them to do so for their students, given the weirdness and worry of this singular time?

\section{Did it work, and would I do it again?}

Participants in this online symposium on eudaimonia and music learning lost in-person contact, participatory live music, meals together, the sense of occasion, and the overall "buzz" that can come from traveling to 
and attending an on-campus experience. As an organizer of the event, my understanding - reinforced through electronic correspondence with participants before, during, and after the event - is that attendees' perceptions reflected the pervasive sense of our not "being there," thus impeding our exploration of some of the affordances of "being apart" (Schroeder et. al, 2008; Smith et. al., 2020) - an imbalance I have herein tried to address. However, despite this I believe participants flourished to an extent in that space. We gained a more equitable and democratic conference experience that enabled the germination of a "community of response" (Pignato, 2017, p. 208), perhaps even a burgeoning community of practice (Wenger, 1998). We shared peer-learning experiences, and these surely allowed some to thrive more than others. Presenters' parents, sisters, spouses, and students all dipped into the event from time to time something they could never do at an on-campus event in a different country with the attendant costs of travel, accommodation, sustenance, socializing, and conference registration fees.

The voices of teachers and music practitioners were as loud as, if not louder than, those of the participating professors. The discussions were less scholarly and less overtly, theoretically philosophical than they likely would have been in an institutional space dominated by those who dwell primarily in those rarefied realms. Often on the planning committees for symposia, colleagues and I ponder how we can connect to practitioners getting their hands dirty with work in the "real world," and listen to their voices and perspectives. I think we came closer to managing that on this occasion, albeit accidentally, and perhaps surprisingly, given the superficially esoteric theme of the conference.

This online symposium was certainly imperfect, in part since it was conducted as a kind of emergency response to the social conditions of spring, 2020. As such it was thus perceived by me and by participants as a kind of second-best, alternative event. But while limited, it was also liminal; while computerized, there was also community. We could not hold the event in an ivory tower, so more people gathered in a more levelling space. Maybe it was still alienating and intimidating to some, but I got the distinct impression that it might not have been. Marissa Silverman (symposium coconvener) and I are working with Dylan van der Schyff on a special issue of an open-access online journal as a follow-up to the symposium. This forum for discussion may by default keep the laity at arm's length, but hopefully this symposium opened a window on to eudaimonia that would have remained closed to many who, gladly, were able to peer through it. Numerous conversations during the symposium and correspondence with attendees afterwards seem to indicate that we inadvertently created a liminal, eudaimonic space that allowed for more flourishing for more people than would have been possible in the intended, traditional symposium 
format. So, do I want to hold future online conferences like this one? I am surprised to find that I think maybe I do.

\section{References}

Abrahams, F. (2020). Choral singing and eudaimonia. In B.J. Winnie (Ed.), The choral conductor's companion: 100 rehearsal techniques, imaginative ideas, quotes, and facts (pp. 3-4). GIA.

Boyce-Tillman, J. (2020). An ecology of eudaimonia and its implications for music education. In G.D. Smith \& M. Silverman (Eds.), Eudaimonia: Perspectives for music learning (pp. 71-89). Routledge.

Cayari, C. (2020). Popular practices for online musicking and performance: Developing creative dispositions for music education and the Internet. Journal of Popular Music Education. DOI: https://doi.org/10.1386/jpme 00018 1.

Conklin, C.N. (2015). The origins of the pursuit of happiness. Washington University Jurisprudence Review, 7(2), 194-262.

Elliott, D.J., \& Silverman, M. (2014). Music, personhood, and eudaimonia: Implications for educative and ethical music education. Journal for Transdisciplinary Research in Southern Africa, 10(2), 59-74.

Frankel, V. (1959). Man's search for meaning. Washington Square Press. Jung, C.G. (1933). Modern man in search of a soul. Routledge.

Li, J., Ghosh, R., \& Nachmias, S. (2020). In a time of COVID-19 pandemic, stay healthy, connected, productive, and learning: words from the editorial team of HRDI, Human Resource Development International, 23(3), 199-207. DOI: $10.1080 / 13678868.2020 .1752493$.

Maslow, A.H. (1962). Toward a psychology of being. Lushena.

Moir, Z., Ferguson, P., \& Smith, G.D. (2016, Dec. 4). Jamming in the third room [conference session]. 11th Art of Record Production Conference, Aalborg University, Aalborg, Denmark.

Norton, D.L. (1976). Personal destinies: A philosophy of ethical individualism. Princeton University Press.

Pignato, J. M. (2017). Situating technology within and without music education. In S.A. Ruthmann \& R. Mantie (Eds.), The Oxford handbook of technology and music. Oxford University Press. DOI: 10.1093/oxfordhb/9780199372133.013.19

Pignato, J.M. \& Begany, G.M. (2015). Deterritorialized, multilocated and distributed: Musical space, poietic domains and cognition in distance collaboration. Journal of Music, Technology \& education, 8(2), 199-217.

Schroeder, F., Renaud, A.B., Rebelo, P., \& Gualdas, F. (2008). Addressing the network: Performative strategies for playing apart." eContact! 10(4) Retrieved from: http://cec.sonus.ca/econtact/10_4/index.html. 
Seligman, M.E.P. (2011). Flourish: A visionary new understanding of happiness and well-being. Simon and Schuster.

Smith, G.D. (2016). (Un)popular music making and eudaimonism. In R. Mantie \& G.D. Smith (Eds.), The Oxford handbook of music making and leisure (pp. 151-170). Oxford University Press.

Smith, G.D. \& Silverman, M.S. (2020). Preface. In G.D. Smith \& M. Silverman (Eds.), Eudaimonia: Perspectives for music learning. Routledge.

Smith, G.D., Moir, Z., Ferguson, P., \& Davies, G. (2020). Low-latency networked music collaborations: Does "good enough" do enough good? Journal of Network Music and Arts, 2(1). Retrieved from: https://commons.library.stonybrook.edu/jonma/vol2/iss1/5/

van der Schyff, D. (2020). Music education and the continuity of mind and life. In G.D. Smith \& M. Silverman (Eds.), Eudaimonia: Perspectives for music learning (pp. 14-39). Routledge.

Waterman, A.S. (1993). Two conceptions of happiness: Contrasts of personal expressiveness (eudaimonia) and hedonic enjoyment. Journal of Personality and Social Psychology 64, pp. 678-691.

Wenger, E. (1998). Communities of practice: Learning, meaning, and identity. Cambridge University Press.

\section{Author Bio}

GARETH DYLAN SMITH is an Assistant Professor of Music at Boston University. His major research interests include popular music education, drumming, sociology of music education, and eudaimonia in relation to musicking. Email: gdsmith@bu.edu 